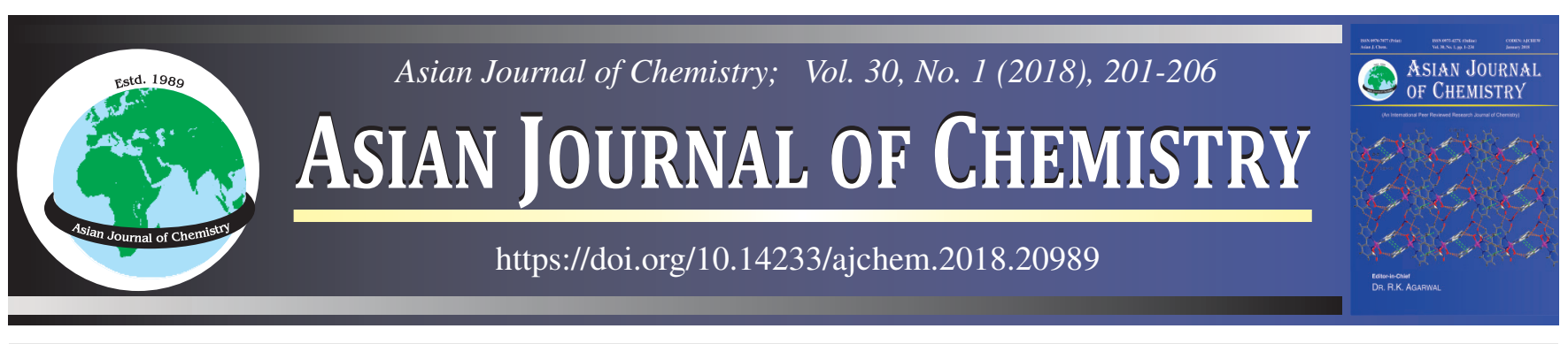

\title{
Dynamic and Rapid Isocratic Greener Analytical Method for Estimation of Chlorocresol along with Azole Compounds in Ointment
}

\author{
N.K. DhiR ${ }^{1}$, D. Chakraborty ${ }^{2}$ and V. KAUR ${ }^{1, *}$
}

${ }^{1}$ Department of Chemistry, Chandigarh University, Gharuan, Mohali-140 413, India

${ }^{2}$ Department of Chemistry, Oxford College of Science, Bangalore-560 102, India

*Corresponding author: E-mail: dean.apc@cumail.in

Received: 21 August 2017;

Accepted: 4 October 2017;

Published online: 30 November 2017;

AJC-18676

\begin{abstract}
The present work describes greener analytical method for the estimation of chlorocresol along with azole compounds, which are used in the manufacturing of derma products. Method is optimized and validated for chlorocresol and miconazole nitrate, clotrimazole taken for identification. Dynamic separation and identification is achieved between 0.69 to 3 min by UPLC method. The UPLC method was validated using an UPLC (BEH RP C18) column with a particle size of $1.7 \mu(50 \mathrm{~mm} \times 2.1 \mathrm{~mm})$ and methanol-buffer (60:40, v/v) as mobile phase by setting the flow rate of $0.4 \mathrm{~mL} / \mathrm{min}$ with isocratic elution. Degradation pathway was optimized and evaluated through PDA and unspecified degradation product from chlorocresol was predicted by Waters Acquity UPLC with Xevo TQD triple quad mass spectrometer from Waters. The UPLC method is shortest time consuming run, suitable for quantifications within good manufacturing practices of the pharma industry and the method is validated according to ICH guidelines.
\end{abstract}

Keywords: UPLC, Greener, Degradation, Validation, TQD/MS/MS.

L

\section{INTRODUCTION}

In pharmaceuticals manufacturing, several drug azoles are used as an antifungal agents in the form of ointment and cream. These major azoles compounds are miconazole nitrate and clotrimazole whereas chlorocresol is a chlorinated phenol, which is used as an antiseptic and preservative during the formulation of these antifungal ointment and cream. These formulations are checked for the potency by validated analytical methods used by the industry. Several HPLC methods, spectroscopy techniques and titration methods are available to estimate these drugs before product release to market, so as to comply with the regulatory authority and for the patient safety $[1,2]$. Methods like RP-HPLC analysis used for the quantification are time consuming and take more time for final product release, which affects the supply chain and end user requirement [3-5]. The present research describes the time efficient method, which can help industry to release the product in shorter time and moreover it decreases the usage of solvents, which is in accordance with green chemistry concept [4]. Chlorocresol method development and analytical validation is a real challenge in the overall study due to low concentration used in formulations about $0.1 \% \mathrm{w} / \mathrm{w}$ which is more sensitive towards gas chromatography analysis. As per pharmacopeia monograph chlorocresol is estimated by gas chromatography for the assay and related substances [5,6]. In the present work, the method is designed to elute chlorocresol by UPLC with shortest run time in finished product where no official monograph is available for the estimation of miconazole, chlorocresol and clotrimazole in UPLC. During this method development activity, other azoles were optimized by this method along with the known impurity from clotrimazole, which involve 2-chlorotritanol. Forced degradation steps are optimized and applied to miconazole nitrate and chlorocresol and found to be well separated from each other under chromatographic conditions within very short span of time. This newly developed analytical method will not only reduce the analytical cost but also taken care of environmental safety aspect by reducing solvent consumption to comply EHS standard and EPA compliances [7]. An overview of the compounds used in the present study discussed below:

Chlorocresol is phenol based chlorinated molecule used as preservative as well as antiseptic for the manufacturing of antifungal creams and ointments. It is an slightly water soluble, dimorphous crystals at room temperature and colourless molecule [8]. Miconazole is synthetic imidazol derivative used as antifungal agent in ointment and cream formulations. It is soluble in dimethyl formamide, dimethyl sulfoxide and slightly soluble in methanol and water [9]. Clotrimazole drug molecule is used for treatment fungal infections as well as other disease like malaria, sickle cell anaemia, beriberi and cancer. It is 
crystalline, lipophilic molecule having $0.49 \mathrm{~g} / \mathrm{L}$ solubility in water [10].

The aim of the current study is to reveal the applicability of UPLC to develop, validate an UPLC/UV method to determine the assay for both miconazole nitrate (as an antifungal) and chlorocresol (as an antimicrobial preservative) in the ointment in support to quality control batch release and can also be used for process validation activity for ointment formulation plant.

\section{EXPERIMENTAL}

Methanol HPLC Grade, orthophosphoric acid (AR grade) and triethyl amine used as a modifier were purchased from Merck (Germany). Water was prepared freshly using a Milli$\mathrm{Q}^{\circledR}$ equipment (Millipore). The reference materials are used as RS USP (United States Pharmacopeia) their purity used $99.40 \%$ for reference standard. Waters UPLC ® BEH RP C18 column with a particle size of $1.7 \mu(50 \mathrm{~mm} \times 2.1 \mathrm{~mm})$ was purchased from Waters Ltd. Ireland $0.22 \mu$ filter was purchased by Millipore Buffer is a mixture of composition of $0.1 \%$ of orthophosphoric acid and $0.1 \%$ of triethyl amine.

Equipment: Throughout the measurements and quantifications, Waters Acquity UPLC ® H class with TUV system with Xevo TQD triple quad Mass spectrophotometer, Empower software from Waters Ltd MILFORD, MA01757 USA was employed. Solvent optimization was Quaternary System Manager (QSM) Controlled by Empower Software.

Chromatographic conditions: The mobile phases were prepared by mixing appropriate amount of UPLC grade methanol and buffer $(0.1 \%$ of orthophosphoric acid and $0.1 \%$ triethylamine in $1000 \mathrm{~mL}$ of Milli-Q water). The mixtures were degassed by sonication for $5 \mathrm{~min}$. The stock solutions of reference standards miconazole and chlorocresol $[5,6]$ were used for standard run UPLC method parameters was set at given in Table-1.

\begin{tabular}{ll}
\multicolumn{2}{c}{ TABLE-1 } \\
\multicolumn{2}{c}{ REPRESENTS THE CHROMATOGRAPHY } \\
CONDITION FOR UPLC SEPARATION \\
\hline Parameters & Conditions \\
\hline Column used for separation & BEH Shield RP-18 $(50 \times 2.1 \mathrm{~cm}) 1.7 \mu \mathrm{m}$ \\
Column temperature & $40{ }^{\circ} \mathrm{C}$ \\
Wavelength & $220 \mathrm{~nm}$ \\
Flow rate & $0.4 \mathrm{~mL} / \mathrm{min}$ \\
Injection volume & $1 \mu \mathrm{L}$ \\
Run time & About 3 min \\
Mobile phase & Buffer:Methanol (40:60)-Isocratic \\
\hline
\end{tabular}

Mobile phase preparation: Buffer solution was prepared by adding $1 \mathrm{~mL}$ of orthophosphoric acid and $1 \mathrm{~mL}$ of triethyl amine were mixed in $1000 \mathrm{~mL}$ of Milli-Q water. For the preparation of mobile phase $400 \mathrm{~mL}$ of buffer solution and $600 \mathrm{~mL}$ of methanol was added to prepare $1000 \mathrm{~mL}$ of mobile phase. It was mixed well and filtered through $0.2 \mu$ filter.

\section{Method validation approach}

Standard validation stocks: Chlorocresol and miconazole nitrate was explored for method validation studies which include specificity, linearity accuracy, Precision, robustness and solution stability as per ICHQ2 guidelines [11].
Stock solution 1: $200 \mathrm{mg}$ of miconazole nitrate as reference standard (RS) was taken in $100 \mathrm{~mL}$ volumetric flask which was dissolved in $75 \mathrm{~mL}$ mobile phase and sonicate for $5 \mathrm{~min}$. Then, it was diluted to $100 \mathrm{~mL}$ with mobile phase.

Stock solution 2: $50 \mathrm{mg}$ of chlorocresol (RS) was taken in $100 \mathrm{~mL}$ volumetric flask and dissolved in $75 \mathrm{~mL}$ mobile phase and sonicated for $5 \mathrm{~min}$. It was then diluted it $100 \mathrm{~mL}$ with mobile phase.

Working standard solution: Working solution of miconazole of $200 \mathrm{ppm}$ and chlorocresol of $50 \mathrm{ppm}$ concentration was prepared from stock solution 1 and 2 , respectively in mobile phase.

Test sample preparation: $2 \mathrm{~g}$ (wt.) of sample was taken in $200 \mathrm{~mL}$ volumetric flask and added $150 \mathrm{~mL}$ of mobile phase and sonicated for $20 \mathrm{~min}$. The solution was heated in a water bath at 40 to $45{ }^{\circ} \mathrm{C}$ for $10 \mathrm{~min}$ by intermediate shaking. The solution was cooled to room temperature and the final volume of $200 \mathrm{~mL}$ was made with mobile phase, which is subjected for sonication for $20 \mathrm{~min}$. It was mixed well and a portion of the solution was passed through $0.2 \mu \mathrm{m}$ syringe filter into an UPLC vial.

System suitability evaluation: The working standard solution was injected six times and the calculated RSD should be $<2 \%$.

Assay of miconazole and chlorocresol: Equal volume of $1 \mu \mathrm{L}$ each of standard, degradation samples and test sample preparation was injected into UPLC for analysis. The chromatograms were recorded and the responses were measured for the major peaks. Degradation summary were evaluated through PDA detector and relevant spectral information, purity was estimated accordingly for azole and chlorocresol.

Mass characterization for chlorocresol degradation impurity profiling: As per pharmacopeia monograph the chlorocresol is estimated through titrimatory methods and the related substances are estimated through gas chromatography [5,6]. The present method is a novel invention for identification of drug substances and its impurity and the process is sustained to the green chemistry principles by reducing solvent usage avoiding gas chromatography in the application of chlorocresol in pharmaceutical industries. The impurities were separated through UPLC after degradation of chlorocreol, which were screened through MS/MS.

Procedure for degradation of chlorocresol: 4-Chlorocresol (2.5 g, $0.0175 \mathrm{~mol})$ was taken in $25 \mathrm{~mL}$ methanol and diluted up to $100 \mathrm{~mL}$ with $0.2 \mathrm{~N} \mathrm{HCl}$. The mixture was refluxed for $8-10 \mathrm{~h}$ at $80^{\circ} \mathrm{C}$ on water bath. Degraded sample was then cooled to room temperature and neutralized with $0.2 \mathrm{~N} \mathrm{NaOH}$ to $\mathrm{pH}$ 7.0. Suitable aliquot (1-2 mL) of this degraded reaction mixture was withdrawn and labelled as sample 1. Remaining solution was then evaporated on a water bath to remove methanol. The reaction mixture was taken in a separating funnel and extracted with chloroform $(100 \mathrm{~mL})$. After extraction the aqueous layer was collected and labelled as sample 2. The organic (chloroform) layer was evaporated to dryness and dissolved in methanol $(10 \mathrm{~mL})$ and labelled as sample 3. Chromatographic study shows that there is a formation of impurity around RT 5.015.

Pure chlorocresol along with sample 1, 2 and 3 were subjected to UPLC and the impurities were identified from UPLC 


\begin{tabular}{llll}
\hline & \multicolumn{3}{c}{ TABLE-2 } \\
& \multicolumn{3}{c}{ REPRESENTS RETURN ON INVESTMENT (UPLC) } \\
\hline \multicolumn{1}{c}{ Elements } & $\begin{array}{c}\text { Traditional HPLC } \\
\text { method }\end{array}$ & $\begin{array}{c}\text { Current UPLC } \\
\text { method }\end{array}$ & \multicolumn{1}{c}{ Comments } \\
\hline Run time & $15 \mathrm{~min} /$ injection & $3 \mathrm{~min} /$ injection & In current UPLC method, run time is $\sim 5$ times shorter \\
Flow rate & $1.5 \mathrm{~mL} / \mathrm{min}$ & $0.4 \mathrm{~mL} / \mathrm{min}$ & In current UPLC method, flow rate is $\sim 3.7$ times shorter \\
Solvent requirement & $315 \mathrm{~mL} / \mathrm{sample}$ & $20 \mathrm{~mL} / \mathrm{sample}$ & In current UPLC method, there is $\sim 16$ times reduction in solvent usage \\
\hline
\end{tabular}

chromatograph and the compound were characterized through Accurate-Mass Quadrupole Time-of-Flight (Q-TOF) LC/MS analysis.

Miconazole nitrate was subjected to oxidation degradation and no other degradation studies were conducted for the same as reported by Abou-Elkheir et al. [12] showed that no degradation was found under acidic, alkaline and thermal degradation conditions for miconazole nitrate.

\section{RESULTS AND DISCUSSION}

Comparison of HPLC and UPLC for miconazole and chlorocresol: Fig. 1(a) represents HPLC chromatogram where the run time was 15 min and elution of standard miconazole eluted at 1.76 and for chlorocresol it was $8.407 \mathrm{~min}$. The same standard of miconazole and chlorocresol was run in UPLC, which shows significant improvement in overall five time reduction in experimental time showed in Fig. 1(b). Table-2 represents overall ROI of UPLC in comparison with HPLC.
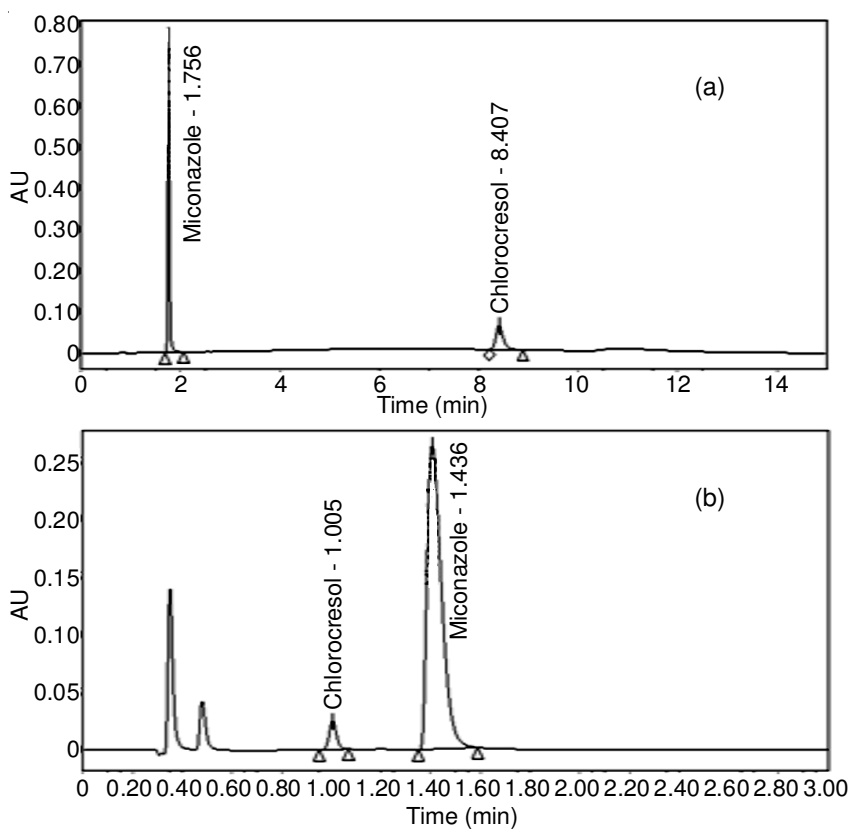

Fig. 1. (a) and (b) represents HPLC chromatogram of chlorocresol and miconazole nitrate by HPLC-run time $15 \mathrm{~min}$ and by UPLC-run time $3 \mathrm{~min}$, respectively

\section{Method validation outcome}

Specificity: Fig. 2(a) and 2(b) demonstrate the specificity of method by identification of miconazole, clotrimazole and chlorocresol, which was separated from each other having no interference due to blank and placebo peak. Table-3 showed PDA results where all peak purity complies with the result and co-elution is obtained throughout the experiments.
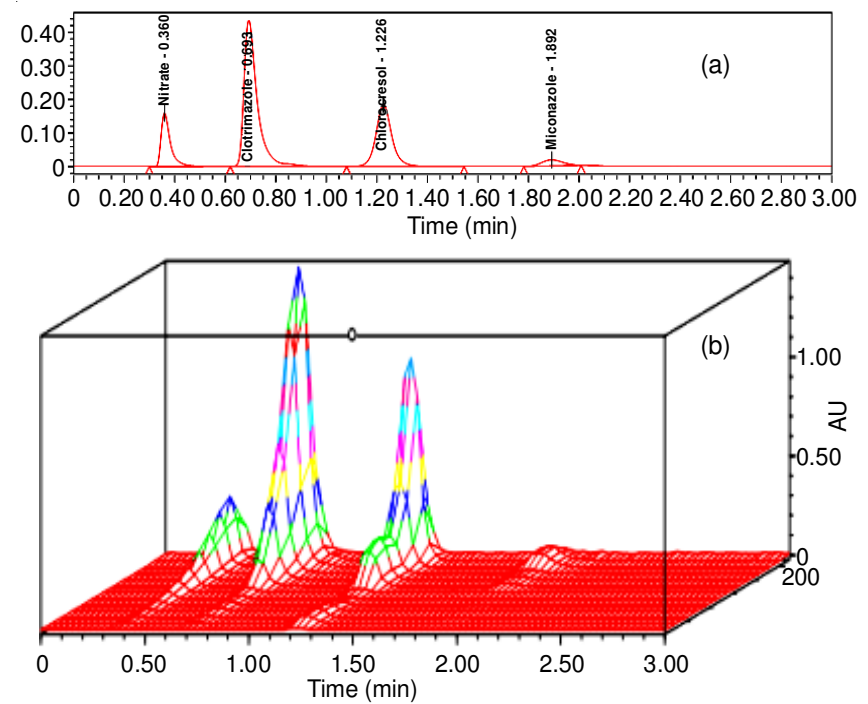

Fig. 2. (a) and (b) represent the UPLC chromatogram and 3D spectrum overview

\begin{tabular}{lcccc}
\multicolumn{5}{c}{ TABLE-3 } \\
\multicolumn{5}{c}{ REPRESENTS THE PEAK PURITY } \\
\hline Name & RT & $\begin{array}{c}\text { Purity 1 } \\
\text { angle }\end{array}$ & $\begin{array}{c}\text { Purity 1 } \\
\text { threshold }\end{array}$ & Purity flag \\
\hline Nitrate & 0.360 & 2.271 & 90.000 & No \\
Clotrimazole & 0.693 & 4.602 & 90.000 & No \\
Chlorocresol & 1.226 & 0.615 & 24.055 & No \\
Miconazole & 1.892 & 10.289 & 90.000 & No \\
\hline
\end{tabular}

Linearity of response: Linearity of chlorocresol and miconazole has been access at the concentration range 80 to $120 \%$ shown in Fig. 3(a) and 3(b), respectively, which was depicted by linear regression analysis revealed correlation coefficients, $\mathrm{r}^{2}=0.999$.

Accuracy: Accuracy analysis (Tables 4 and 5) indicates the RSD percent recovery is 0.41 to 0.96 for chlorocresol and miconazole, respectively and both are within the acceptance limit.

Precision: System, method precision and intermediate precision were checked and found in within acceptable RSD $<2 \%$.

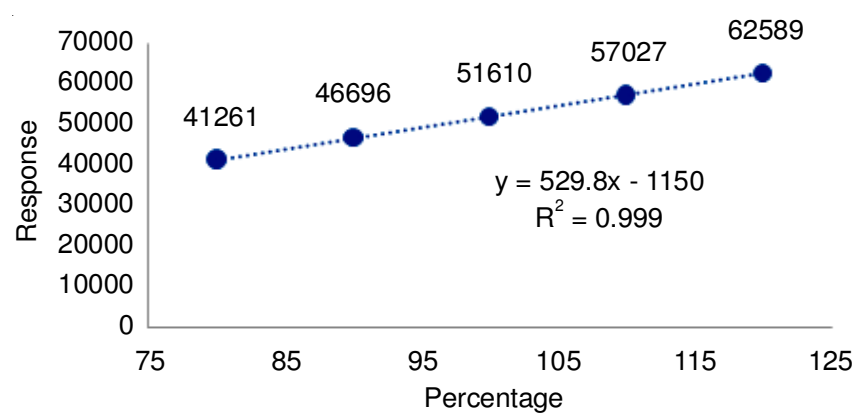

Fig. 3a. Linearity optimization for chlorocresol from 80 to $120 \%$ concentration 


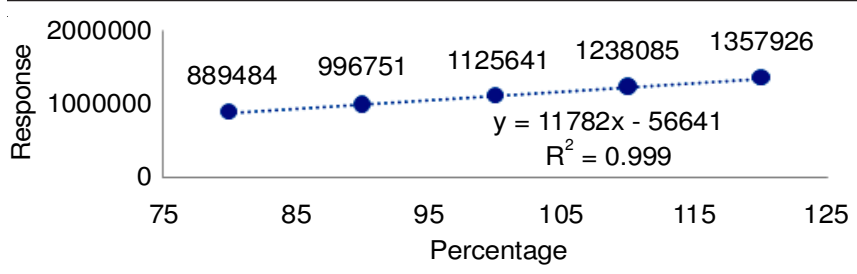

Fig. 3b. Linearity optimization for miconazole from 80 to $120 \%$ concentration

TABLE-4

REPRESENTS ACCURACY DATA OF CHLOROCRESOL

\begin{tabular}{|c|c|c|c|c|c|}
\hline \multicolumn{6}{|c|}{ Chlorocresol recovery $(\%)$} \\
\hline $\begin{array}{c}\text { Nominal } \\
(\%)\end{array}$ & $\begin{array}{c}\text { Recovery } \\
(\%)\end{array}$ & Differnece & Results & $\begin{array}{c}\text { Std. } \\
\text { deviation }\end{array}$ & RSD \\
\hline \multirow{3}{*}{80} & 80.9 & 0.9 & 101.1 & \multirow{3}{*}{0.557} & \multirow{3}{*}{0.55} \\
\hline & 80.3 & 0.3 & 100.4 & & \\
\hline & 80.0 & 0 & 100.0 & & \\
\hline \multirow{3}{*}{100} & 100.5 & 0.5 & 100.5 & \multirow{3}{*}{0.252} & \multirow{3}{*}{0.25} \\
\hline & 100.3 & 0.3 & 100.3 & & \\
\hline & 100.0 & 0 & 100.0 & & \\
\hline \multirow{3}{*}{120} & 120.3 & 0.3 & 100.3 & \multirow{3}{*}{0.379} & \multirow{3}{*}{0.38} \\
\hline & 120.3 & 0.3 & 100.3 & & \\
\hline & 119.6 & 0.4 & 99.7 & & \\
\hline & & Avg & 100.4 & & \\
\hline & & d. deviation & 0.968 & & \\
\hline & & RSD & 0.41 & & \\
\hline
\end{tabular}

Robustness: Method was challenged by variation in flow rates, temperature and strength of solvent in mobile phase $\pm 10 \%$. Table- 6 revealed that the assay percentage is within the acceptance range where RSD is $<2 \%$.

Stability of analytical solution: The results are shown in Table-7 for the chlorocresol and miconazole sample stable

\begin{tabular}{|c|c|c|c|c|c|}
\hline \multicolumn{6}{|c|}{$\begin{array}{c}\text { TABLE-5 } \\
\text { REPRESENTS ACCURACY DATA OF MICONAZOLE }\end{array}$} \\
\hline \multicolumn{6}{|c|}{ Miconazole recovery $(\%)$} \\
\hline $\begin{array}{c}\text { Nominal } \\
(\%)\end{array}$ & $\begin{array}{c}\text { Recovery } \\
(\%)\end{array}$ & Differnece & Results & $\begin{array}{c}\text { Std. } \\
\text { deviation }\end{array}$ & RSD \\
\hline \multirow{3}{*}{80} & 81.4 & 1.4 & 101.7 & \multirow{3}{*}{0.265} & \multirow{3}{*}{0.26} \\
\hline & 81.3 & 1.3 & 101.6 & & \\
\hline & 81.0 & 1 & 101.2 & & \\
\hline \multirow{3}{*}{100} & 99.5 & 0.5 & 99.5 & \multirow{3}{*}{0.20} & \multirow{3}{*}{0.20} \\
\hline & 99.3 & 0.7 & 99.3 & & \\
\hline & 99.1 & 0.9 & 99.1 & & \\
\hline \multirow{6}{*}{120} & 120.4 & 0.4 & 100.4 & \multirow{3}{*}{0.058} & \multirow{3}{*}{0.06} \\
\hline & 120.4 & 0.4 & 100.4 & & \\
\hline & 120.4 & 0.4 & 100.3 & & \\
\hline & & Avg & 100.4 & & \\
\hline & & d. deviation & 0.968 & & \\
\hline & & RSD & 0.96 & & \\
\hline
\end{tabular}

upto $48 \mathrm{~h}$ at room temperature within the acceptance not more than $2 \%$ RSD.

Filter variability: Result obtained in Table- 8 shows difference not more than $1.5 \%$, which is within the acceptance range and it does not affect the results.

MS/MS outcome: Table-9 depicts the ESI negative ion mode data. Impurities shown same fragments of parent $\mathrm{m} / \mathrm{z} 141$

TABLE-8

REPRESENTS FILTER VARIABILITY OF CHLOROCRESOL AND MICONAZOLE FOR UPLC

\begin{tabular}{cccc}
\hline Content & $\begin{array}{c}\text { Membrane } \\
\text { filter }(\%)\end{array}$ & $\begin{array}{c}\text { Nylon filter } \\
(\%)\end{array}$ & $\begin{array}{c}\text { Difference } \\
(\%)\end{array}$ \\
\hline Miconazole & 100.7 & 101.0 & 0.3 \\
Chlorocresol & 97.0 & 98.5 & 1.5 \\
\hline
\end{tabular}

\begin{tabular}{|c|c|c|c|c|c|}
\hline \multicolumn{6}{|c|}{$\begin{array}{c}\text { TABLE-6 } \\
\text { DEPICTS ROBUSTNESS OF CHLOROCR }\end{array}$} \\
\hline \multirow{2}{*}{ Parameter } & & \multicolumn{2}{|c|}{ Retention time (min) } & \multicolumn{2}{|c|}{ Assay $(\%)$} \\
\hline & & Chlorocresol & Miconazole & Chlorocresol & Miconazole \\
\hline \multirow{2}{*}{$\begin{array}{l}\text { Change in flow rate }(0.4 \\
\mathrm{mL} / \mathrm{min} \pm 0.05 \mathrm{~mL} / \mathrm{min})\end{array}$} & $0.36 \mathrm{~mL} / \mathrm{min}$ & 1.17 & 1.37 & 97.7 & 103.5 \\
\hline & $0.44 \mathrm{~mL} / \mathrm{min}$ & 0.91 & 1.27 & 97.2 & 104.4 \\
\hline \multirow{2}{*}{ Column temperature } & $36^{\circ} \mathrm{C}$ & 1.04 & 1.47 & 97.2 & 102.7 \\
\hline & $44^{\circ} \mathrm{C}$ & 0.96 & 1.32 & 97.3 & 103.5 \\
\hline \multirow{2}{*}{ Mobile phase } & $-10 \%$ & 0.81 & 0.93 & 98.7 & 101.0 \\
\hline & $+10 \%$ & 1.18 & 1.86 & 100.6 & 102.1 \\
\hline RSD for assay (\%) & & & & 1.37 & 1.17 \\
\hline
\end{tabular}

\begin{tabular}{|c|c|c|c|c|c|c|c|c|}
\hline \multicolumn{9}{|c|}{$\begin{array}{l}\text { TABLE-7 } \\
\text { STABILITY OF ANALYTICAL SOLUTION OF CHLOROCRESOL AND MICONAZOLE }\end{array}$} \\
\hline & \multicolumn{4}{|c|}{ Chlorocresol } & \multicolumn{3}{|c|}{ Miconazole } & \multirow[b]{2}{*}{ Difference } \\
\hline \multirow{2}{*}{ Time } & Initial results & After $24 \mathrm{~h}$ & After $48 \mathrm{~h}$ & RSD & Initial results & After $24 \mathrm{~h}$ & After $48 \mathrm{~h}$ & \\
\hline & 100.5 & 98.7 & 98.5 & 1.11 & 101.8 & 102.8 & 100.3 & 1.24 \\
\hline \multicolumn{9}{|c|}{$\begin{array}{c}\text { TABLE-9 } \\
\text { REPRESENTS ESI NEGATIVE ION MODE DATA }\end{array}$} \\
\hline Sample & $m / z$ & Daughters & Daughters & Daughters & Daughters & Daughters & Daughters & Daughters \\
\hline Pure sample & 141 & 63 & 71 & 77 & 105 & & & \\
\hline \multirow{2}{*}{ Sample 1} & 221 & 71 & 77 & 105 & 121 & 134 & 147 & 177 \\
\hline & 141 & 63 & 71 & 77 & 105 & & & \\
\hline \multirow{2}{*}{ Sample 2} & 221 & 71 & 77 & 105 & 121 & 134 & 147 & 177 \\
\hline & 141 & 63 & 71 & 77 & 105 & & & \\
\hline \multirow{2}{*}{ Sample 3} & 221 & 71 & 77 & 105 & 121 & 134 & 147 & 177 \\
\hline & 141 & 63 & 71 & 77 & 105 & & & \\
\hline
\end{tabular}


and $m / z, 221$ having daughters 71,77 and 105 shows structural similarity (Figs. 4 and 5). In positive mode $\mathrm{m} / \mathrm{z} 212$ and 223 was seen in all three impurities and $m / z 212$ and 223 share common fragment in all samples represented in Table-10 (Figs.
6 and 7). $m / z 237,277$ and 295 additionally seen in sample 3 which has the same fragments as $m / z 223$ in positive ion mode shown in Table-10. Fig. 8 corresponds to predicted structure of unspecified impurity obtained from degradation of chlorocresol.

\begin{tabular}{|c|c|c|c|c|c|c|c|}
\hline \multicolumn{8}{|c|}{$\begin{array}{c}\text { TABLE-10 } \\
\text { REPRESENTS ESI POSITIVE ION MODE DATA }\end{array}$} \\
\hline Sample & $m / z$ & Daughters & Daughters & Daughters & Daughters & Daughters & Daughters \\
\hline \multirow{2}{*}{ Sample 1} & 212 & 136 & 168 & 194 & - & - & - \\
\hline & - & 57 & 149 & - & - & - & - \\
\hline \multirow{2}{*}{ Sample 2} & 212 & 92 & 109 & 124 & 136 & 168 & 194 \\
\hline & 223 & 57 & 149 & - & - & - & - \\
\hline \multirow{5}{*}{ Sample 3} & 223 & 57 & 149 & - & - & - & - \\
\hline & 237 & 57 & 149 & 163 & 205 & - & - \\
\hline & 277 & 57 & 149 & 161 & 175 & 203 & - \\
\hline & 295 & - & 149 & - & 175 & 203 & - \\
\hline & 317 & 114 & 254 & 261 & - & - & - \\
\hline
\end{tabular}

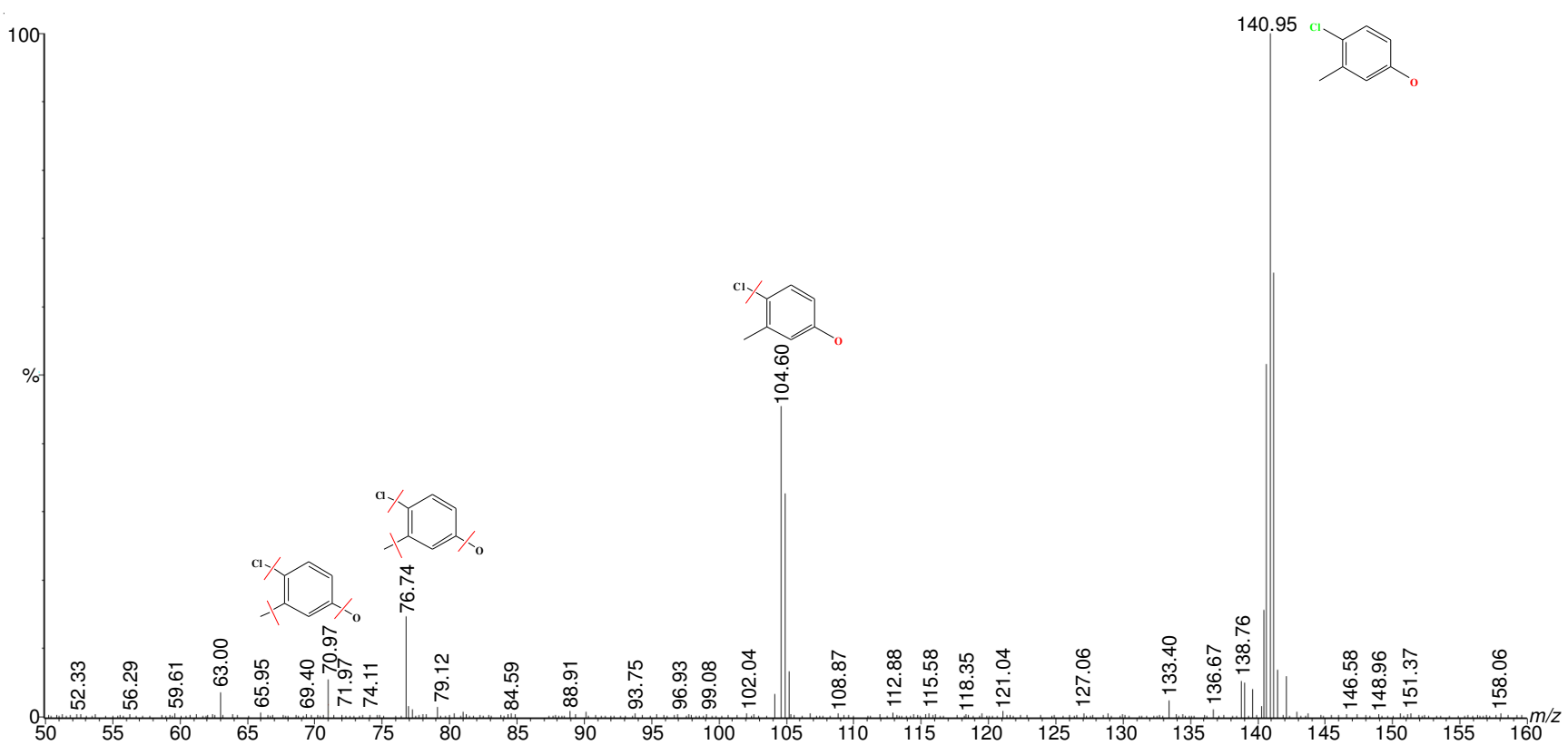

Fig. 4. Fragmentation interpretation of 141 in negative ion mode

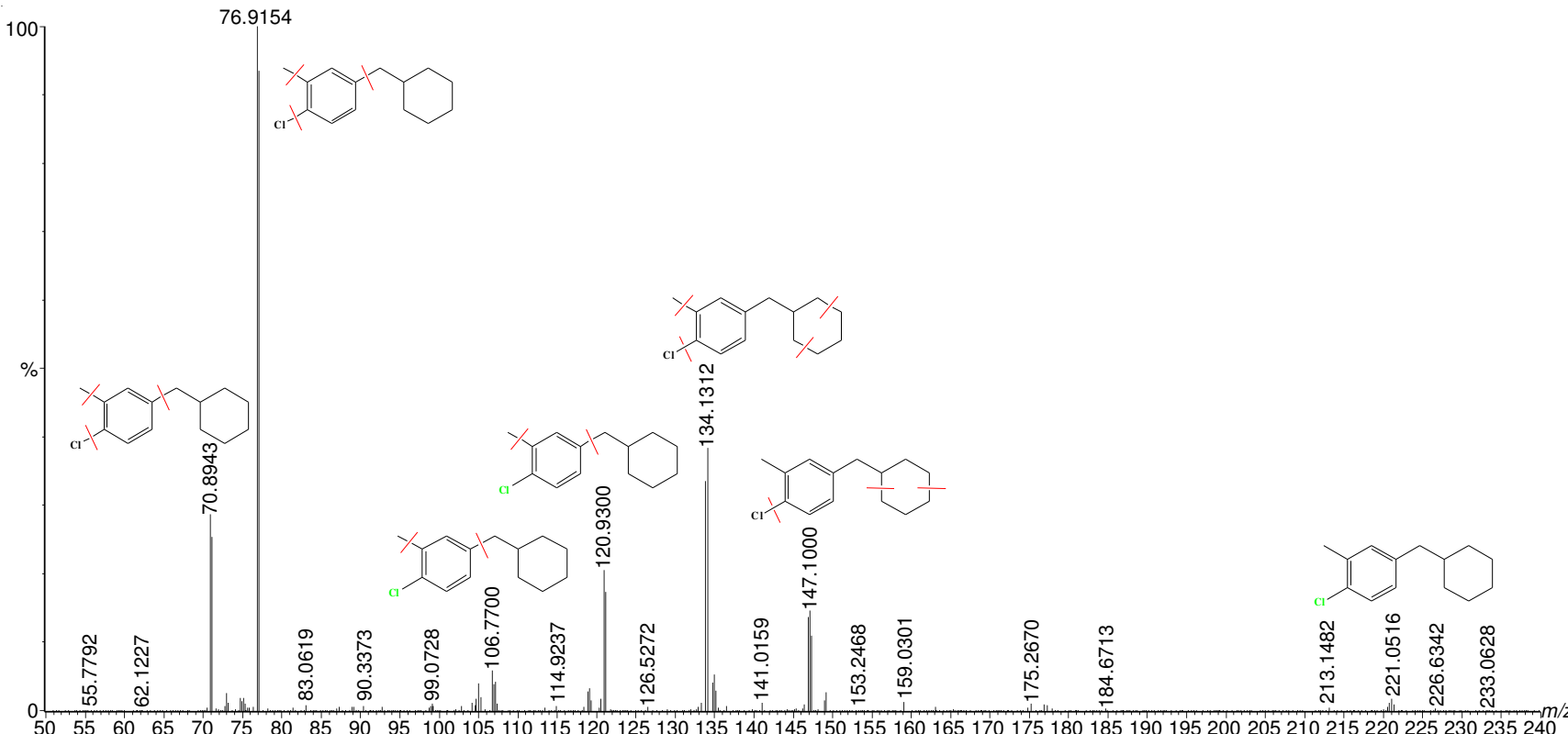

Fig. 5. Fragmentation interpretation of 221 in negative ion mode 


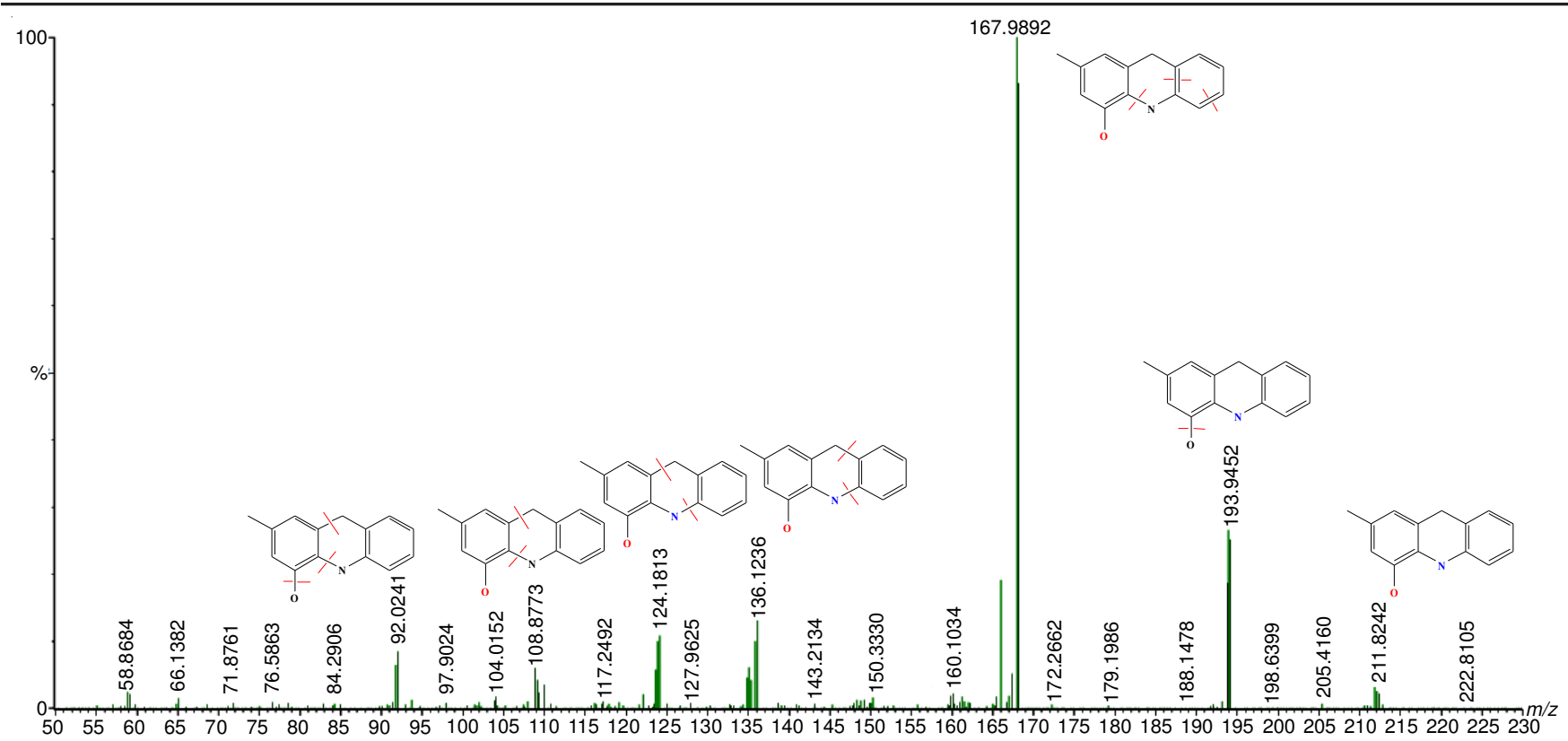

Fig. 6. Fragmentation interpretations of 212 in positive ion mode

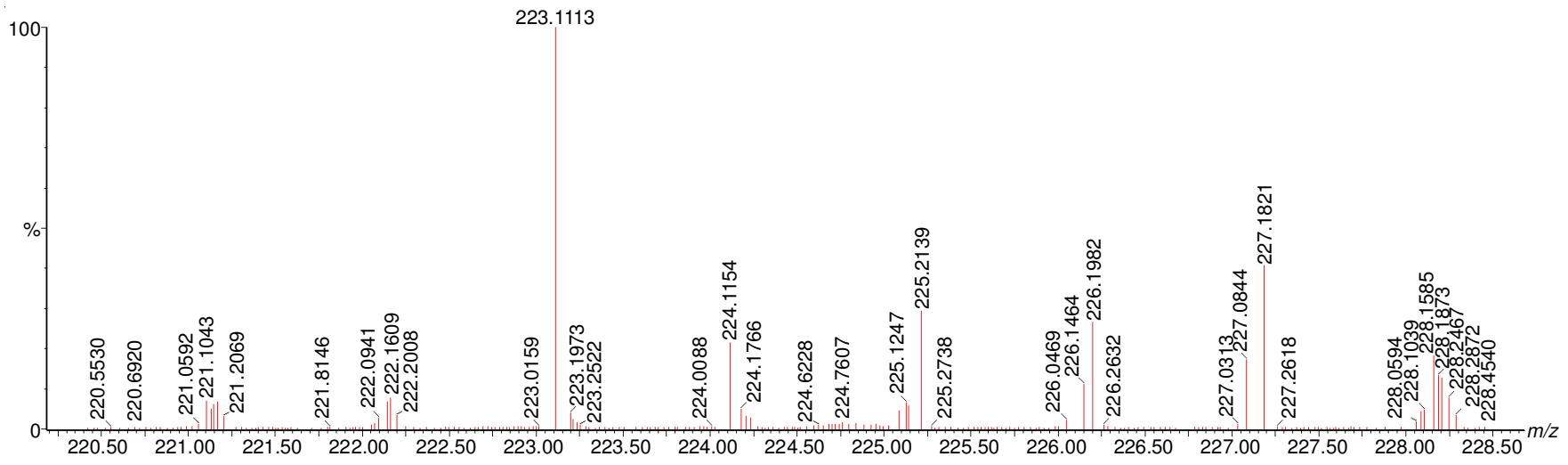

Fig. 7. Probable elemental composition predicated in positive ion mode for 223

\section{Conclusion}

On the basis of this study, it appears that the use of this currently developed UPLC method for the quantification of miconazole (or clotrimazole) and chlorocresol in antifungal ointment and cream is much faster and robust method as compare to HPLC analysis in product formulation area is practical. The time reduction and solvent saving characteristics of current UPLC method are very advantageous, compared to the most widely used conventional HPLC technique. The enhanced sensitivity of the UPLC-UV method compared to conventional HPLC does not necessitate the use of a mass spectrometry detector, which is expensive. The concept of applying this generic method for several API is feasible and practical if the structure and properties of compounds to be determined are of similar type.<smiles>Cc1cc([CH]C2CCCCC2)ccc1Cl</smiles>

Fig. 8. Represented unspecified predicted impurity; m.f.: $\mathrm{C}_{14} \mathrm{H}_{19} \mathrm{Cl}$; exact mass: 222.12; m.w. 222.75; Elemental composition: C, 75.49; H, 8.60; Cl, 15.92

\section{REFERENCES}

1. N.J. Dhir and S.K. Yadav, J. Indian Chem. Soc., 89, 1665 (2012).

2. N. Dhir, D. Chakraborty and V. Kaur, Patent filing number: 4299/DEL/ 2015.

3. S.E. Johnston, N.L. Gill, Y.C. Wei, R. Markovich and A.M. Rustum, J. Chromatogr. Sci., 48, 733 (2010); https://doi.org/10.1093/chromsci/48.9.733.

4. N. O'Connor, M. Geary, M. Wharton and P. Sweetman, J. Chromatogr. Sci., 50, 199 (2012);

https://doi.org/10.1093/chromsci/bmr047.

5. European Pharmacopeia, version 8, vol. 2 (2015).

6. British Pharmacopeia, version 8, vol. 1, p. 519 (2015).

7. P.J. Dunn, A. Wells and M.T. Williams, Green Chemistry in the Pharmaceutical Industry, Wiley-VCH Verlag GmbH \& Co (2010).

8. $p$-Chloro- $m$-cresol [MAK Value Documentation, 1991]. The MAK Collection for Occupational Health and Safety, 272 (2012).

9. A.A. Al-Badr, Profiles Drug Subst. Excip. Relat. Methodol., 32, 3 (2005); https://doi.org/10.1016/S0099-5428(05)32007-7.

10. S. Kadavakollu, C. Stailey, C.S. Kunapareddy and S. White, Med. Chem. (Los Angeles), 4, 722 (2014); https://doi.org/10.4172/2161-0444.1000219.

11. ICH Harmonized Tripartite Guideline, Validation of Analytical Procedures: Methodology (1996).

12. A. Abou-elkheir, H.M. Saleh, M. Magda, B.S. Ghareeb and M.S. Mohram, Indo-Am. J. Pharm. Sci., 5, 641 (2015). 